\title{
Bipolar sealer can reduce intraoperative blood loss and transfusion in major orthopedic surgery: a meta-analysis and trial sequence analysis
}

\author{
Zhan Wang ${ }^{1}$, Ai-Xian Tian ${ }^{2,3}$, Kai-Qiang Feng ${ }^{1}$, Qingsong Wang ${ }^{4}$ and Yi Wang ${ }^{1}$ \\ ${ }^{1}$ Department of Clinical Laboratory, Tianjin Hospital, Tianjin University, Tianjin, 300211, People's Republic of China \\ ${ }^{2}$ Orthopaedics Institute, Tianjin Hospital, Tianjin University, Tianjin, 300211, People's Republic of China \\ ${ }^{3}$ Tianjin Hospital, Tianjin University, Tianjin, 300211, People's Republic of China \\ ${ }^{4}$ Tianjin Research Center of Basic Medical Sciences, School of Basic Medical Sciences, Tianjin Medical University, Tianjin, \\ 300070, People's Republic of China
}

Correspondence to: Yi Wang, email: 3066751851@qq.com

Qingsong Wang, email: wqshty@163.com

Keywords: bipolar sealer; orthopedic surgery; meta-analysis

Received: August 19, $2017 \quad$ Accepted: November 14, $2017 \quad$ Published: January 04, 2018

Copyright: Wang et al. This is an open-access article distributed under the terms of the Creative Commons Attribution License 3.0 (CC BY 3.0), which permits unrestricted use, distribution, and reproduction in any medium, provided the original author and source are credited.

\section{ABSTRACT}

To evaluate the efficacy and safety of bipolar sealer for the reduction of intraoperative blood loss and transfusion requirements for patients undergoing major orthopedic surgery, including total knee arthroplasty (TKA), total hip arthroplasty (THA), and spinal surgery. Electronic databases, including PubMed, Embase, CENTRAL (Cochrane Controlled Trials Register), Web of Science and Google scholar, were searched within a date range from their inception up to November 2016. The intraoperative blood loss, hemoglobin drop, operation time and length of hospital stay were calculated as the weighted mean difference (WMD) with a $95 \%$ confidence interval (CI), and the need for transfusion as well as the occurrence of infection were calculated as relative risk (RR) with a $95 \% \mathrm{CI}$. The results indicated that bipolar sealer can decrease intraoperative blood loss (WMD $=-105.30,95 \%$ CI $-169.17 \sim-41.43$; $P<0.00001)$, the need for a transfusion (RR, 0.68; 95\% CI, 0.53 0.86; $P=0.001)$, and hemoglobin drop (WMD, $-0.14 ; 95 \% \mathrm{CI},-0.27-0.00 ; P=0.05)$. There were no significant differences between operation time, the length of the hospital stay and the occurrence of infection $(P>0.05)$. Compared to standard electrocautery, bipolar sealer can effectively reduce intraoperative blood loss and subsequent blood transfusion without increasing the rate of infections.

\section{INTRODUCTION}

Major orthopedic surgery, including total knee arthroplasty (TKA), total hip arthroplasty (THA), and spinal surgery, are associated with significant blood loss and subsequent blood transfusions [1]. The amount of blood loss after TKA has varied from $900 \mathrm{~mL}$ to $2000 \mathrm{~mL}$, and the percentage of patients who need a blood transfusion can be as high as $39 \%$ [2-3]. For THA, the blood loss ranges from $1000 \mathrm{~mL}$ to $2000 \mathrm{~mL}$, and the percentage of patients who require a blood transfusion can be as high as $40 \%$ [4]. It has been reported that the total perioperative blood loss during posterior spinal fusion ranges from 600 to $1500 \mathrm{~mL}$ [5-
7]. Blood transfusion carries a risk of immunological and non-immunological adverse effects and can even increase mortality [8-10]. Surgical blood loss is an important component of perioperative total blood loss in major orthopedic surgery. Numerous studies have investigated the efficacy of bipolar sealer for reducing intraoperative blood loss and transfusion requirements in patients undergoing orthopedic surgery with varying results $[11,13]$. Thus, we conducted a meta-analysis of randomized controlled trials to assess the effectiveness and safety of bipolar sealer for reducing intraoperative blood loss and transfusion requirements in major orthopedic surgery, including knee, hip, and spinal procedures. 


\section{MATERIALS AND METHODS}

\section{Search strategies}

PubMed, Embase, and Cochrane Database of Systematic Reviews, Web of Science and Google scholar were searched within a date range from inception of the databases up to November 2016. The search terms included "bipolar sealer", "total knee arthroplasty", "total hip arthroplasty" and "spinal surgery". Manufacturer documentation and published reviews were also reviewed for additional studies. There were no restrictions on the publication dates or language. Search strategies can be obtained in Supplementary Table 1.

\section{Inclusion criteria and exclusion criteria}

Studies were included if they met the following criteria: (i) participants underwent orthopedic surgery, including TKA, THA and spinal surgery; (ii) patients were randomly assigned to the treatment group with bipolar sealer and the control group received standard electrocautery; (iii) the study measured the following outcomes: intraoperative blood loss, the need for transfusion, hemoglobin drop, operation time, length of hospital stay and the occurrence of infection; and (iv) the study was an RCT.

Studies were excluded if they were non-RCTs, letters, meeting abstracts or did not have sufficient data for the meta-analysis.

\section{Study selection}

The initial electronic database searches for identifying potential studies to include based on title and abstract information were performed by two independent authors. Complete study reports were assessed independently by both authors. If there was insufficient data, the authors of the study were contacted by e-mail or telephone for more information and to clarify the data. Any disagreement was resolved by consensus or a consultation with the senior author. References and data for each included study were carefully rechecked to ensure that no overlapping data were present.

\section{Data extraction}

Data were extracted from the included studies and recorded in a pre-generated standard Microsoft ${ }^{\circledR}$ Excel (Microsoft Corporation, Redmond, Washington, USA) file by two independent authors. Any disagreement was resolved by consensus or consultation with the senior author. The data that were extracted included the author and publication year, case and mean age of the bipolar sealer and standard electrocautery, transfusion criteria, operation approach, follow-up, surgical methods and outcomes. If the data were not reported numerically, we extracted them using the Software "Getdata Graph Digitizer" to analyze the published figures [14].

\section{Quality assessment}

The Cochrane risk of bias tool was used to evaluate the risk of bias [15]. Two authors independently reviewed all included RCTs and the following categories: selection bias (random sequence generation and allocation concealment), performance bias, detection bias, attrition bias, reporting bias and other bias. The biases were graded according to risk as 'high', 'low' or 'unclear'. All discrepancies were resolved by consensus or in consultation with the senior author. Kappa values was calculated by 2 reviewers and were rated as follows: fair, 0.40 to 0.59 ; good, 0.60 to 0.74 ; and excellent, 0.75 or higher [16].

\section{Quality of evidence assessment}

Two reviewers independently evaluated the quality of evidence assessment in accordance with the Grading of Recommendations Assessment, Development and Evaluation (GRADE) methodology [17]. Risk of bias, inconsistency, indirectness, imprecision and publication bias were the assessment items [17, 18]. Each result was classified as high, moderate, low, or very low. GRADE Pro software was used to construct summary tables for the included studies.

\section{Statistical analyses}

Review Manager software (version 5.3.0; The Nordic Cochrane Centre, Copenhagen, Denmark) was used to analyze the results. Continuous data (intraoperative blood loss, hemoglobin drop, operating time, length of hospital stay) was calculated as a weighted mean difference (WMD) with a 95\% confidence interval (CI). Dichotomous data (i.e., the need for transfusion and the occurrence of infection) were expressed as relative risk (RR) with a 95\% CI. Statistical heterogeneity was assessed using the $\mathrm{I}^{2}$ value. An $\mathrm{I}^{2}$ value $>50 \%$ was considered to suggest statistical heterogeneity and random effects modeling was performed. Otherwise, a fixed effects approach was used. Subgroup analysis was performed according to surgical category and the quality of the included studies. A $P$ value less than 0.05 was considered to indicate a significant difference.

\section{Trial sequential analysis}

Trial sequential analyses were performed with trial sequential analysis version 0.9.5.5 beta (www.ctu.dk/tsa). Due to sparse data and repetitive testing of cumulative data, traditional meta-analyses have a risk of random errors 
[19-21]. Thus, trial sequential analysis was necessary if the final results were too sparse to reach firm conclusions. Trial sequential analysis is comparable to interim analysis in a single trial, and the trial sequential monitoring boundary can be applied to meta-analysis to determine whether the $P$ value is small enough to show the anticipated effect and whether the trial should be terminated early [22]. If the cumulative z-curve trial crossed the sequential analysis boundary or the futility zone was crossed, more trials were not needed to change the final conclusion.

\section{RESULTS}

\section{Search results}

Initially, a total of 238 studies were identified, and 183 studies were screened after duplicates were removed. A total of 164 papers were excluded according to the title and abstracts. Then, a total of 7 non-RCTs were excluded according to the inclusion and exclusion criteria. Finally, we identified 12 RCTs with 1130 patients (bipolar sealer $=555$, standard electrocautery $=575)$ that were associated with orthopedic surgery [11, 12, 23, 32] (Figure 1). A total of 6 studies involved THA [11, 28, 32], 3 studies involved TKA $[12,23,24]$, and 3 studies involved spinal surgery $[25,27]$. The number of patients included in the studies ranged from 25 to 100 . The mean age of the patients in the included studies ranged from 55.4 to 73.3. The ages of the male patients ranged from 13 to 66 . The general characteristics of the included studies are shown in Table 1.

\section{Quality assessment}

The quality assessment of the included RCTs is shown in Figure 2 and Figure 3. Random sequence generation were conducted adequately in 5 studies [23, $25,28,32]$ and allocation concealment was performed adequately in 5 studies [11, 23, 24, 28, 32]. Because it was impossible to blind the participants and surgeons who performed the surgery, all outcomes had an unclear risk of bias for this domain $[11,12,23,32]$. The detection bias was low in 6 studies $[11,23,25,28,30]$, and the rest had unclear risk bias [12, 24, 26, 27, 31, 32]. Attrition bias, reporting bias and other biases were low in 9 studies [11, 12, 23, 25, $28,32]$ and the remaining 3 studies all had unclear bias [24, $26,27]$. The overall kappa value was 0.704 .

\section{Quality of evidence assessment}

A summary of the quality of the evidence according to the GRADE approach is shown in Supplementary Table 2. The GRADE level of evidence was low for intraoperative blood loss, and it was moderate for the need for transfusion, hemoglobin drop, operation time, length of hospital stay and the occurrence of infection.

\section{Intraoperative blood loss}

Total blood loss was examined in 10 trials [11, $23,28,30,32]$ with 955 patients. These trials randomly selected 479 patients to receive bipolar sealer and 476 patients to received standard electrocautery. A pooled WMD for all patients was completed, and the data showed there was significant heterogeneity $\left(\mathrm{I}^{2}=94 \%\right)$. Compared to standard electrocautery, bipolar sealer was associated with less total blood loss by a mean of $105.30 \mathrm{~mL}(95 \%$ CI, -169.17 to $-41.43 ; P<0.00001$, Figure 4$)$. The subgroup analysis results are presented in Table 2. Funnel plot results for intraoperative blood loss are shown in Figure 5. TSA demonstrated that the required information size was reached, and the cumulative z-curve crossed the traditional boundary, which indicated that additional studies were not needed and would be unlikely to change the conclusions (Figure 6).

\section{The need for transfusion}

Data on blood transfusion were available in 8 studies $[11,12,23,26,28,30,32]$, which included a total of 848 patients. A pooled RR for all patients was completed and the data showed there was no significant heterogeneity $\left(\mathrm{I}^{2}=31.7 \%\right)$. Bipolar sealer reduced the probability of receiving a blood transfusion by $9.25 \%$ (RR, 0.68; 95\% CI, 0.53-0.86; $P=0.001$, Figure 7). Funnel plot results for the need for transfusion are shown in Figure 8. The cumulative z-curve crossed the traditional boundary, but not the trial sequential monitoring boundary and did not reach the required information size, which suggested there was a need for more evidence to establish whether bipolar sealer was associated with less intraoperative blood loss compared to standard electrocautery (Figure 9).

\section{Hemoglobin drop}

Data on hemoglobin drop were available for 9 trials $[11,12,23,24,26,28,30,32]$, including a total of 911 patients. A pooled WMD for all patients was completed, and the data showed no significant heterogeneity ( $\mathrm{I}^{2}$ $=26.0 \%$ ). Bipolar sealer was associated with less hemoglobin drop compared to standard electrocautery (WMD, -0.14; 95\% CI, -0.27-0.00; $P=0.05$, Figure 10).

\section{Operation time}

Data on operation time were available for 7 trials $[24,26,28,31,32]$, which involved 627 patients. A pooled WMD for all patients was completed, and the data showed no significant heterogeneity $\left(\mathrm{I}^{2}=34.0 \%\right)$. Bipolar sealer was associated with lower operating times compared to standard electrocautery (WMD, $-1.96 ; 95 \% \mathrm{CI},-5.46$ to $1.53 ; P=0.27$, Figure 11). 
Table 1: The general characteristic of the included studies

\begin{tabular}{|c|c|c|c|c|c|c|c|c|}
\hline $\begin{array}{l}\text { Author and } \\
\text { year }\end{array}$ & $\begin{array}{l}\text { Case } \\
(\mathrm{BP} / \mathrm{C})\end{array}$ & $\begin{array}{l}\text { Mean age } \\
(\mathrm{BP} / \mathrm{C})\end{array}$ & $\begin{array}{l}\text { Male patients } \\
\text { (BP/C) }\end{array}$ & $\begin{array}{c}\text { Transfusion } \\
\text { criteria }\end{array}$ & Operation approach & follow-up & Surgical methods & Outcomes \\
\hline Marulanda 2008 & $25 / 25$ & $57 / 56$ & $13 / 14$ & NS & $\begin{array}{l}\text { Antero-lateral } \\
\text { approach }\end{array}$ & NS & THA & $1,2,3,5,6$ \\
\hline Barsoum 2011 & $71 / 69$ & $55.4 / 55.7$ & $36 / 38$ & $\mathrm{Hb}<7.0 \mathrm{~g} / \mathrm{dl}$ & $\begin{array}{l}\text { Standard posterior } \\
\text { approach and } \\
\text { modified direct } \\
\text { lateral } \\
\text { approach }\end{array}$ & 3 months & THA & $1,2,3,4,5,6$ \\
\hline Zeh 2010 & $55 / 50$ & $63.7 / 68.3$ & $15 / 20$ & NS & $\begin{array}{c}\text { Watson-Jones } \\
\text { approach and } \\
\text { standard Bauer } \\
\text { approach }\end{array}$ & NS & THA & $1,4,5$ \\
\hline Morris 2013 & $100 / 100$ & $63.5 / 61.3$ & $48 / 48$ & NS & $\begin{array}{l}\text { Anterior supine } \\
\text { intermuscular } \\
\text { approach }\end{array}$ & 1.5 months & THA & $1,2,3$ \\
\hline Falez 2013 & $26 / 38$ & NS & NS & NS & NS & NS & THA & 6 \\
\hline Suarez 2015 & $57 / 61$ & $65.7 / 64.7$ & $27 / 19$ & $\mathrm{Hb}<8.0 \mathrm{~g} / \mathrm{dl}$ & $\begin{array}{l}\text { Direct anterior } \\
\text { approach }\end{array}$ & NS & THA & $1,2,3,4,5$ \\
\hline Marulanda 2009 & $35 / 34$ & $66 / 66$ & $22 / 23$ & NS & NS & 3 month & TKA & $1,2,3,5,6$ \\
\hline Plymale 2012 & $50 / 61$ & $38 / 51$ & $64 / 66$ & NS & NS & 2 days & TKA & $2,3,6$ \\
\hline Seviciu 2016 & $31 / 32$ & $64.8 / 62.9$ & $14 / 14$ & $\mathrm{Hb}<7 \mathrm{~g} / \mathrm{dl}$ & Mini-midvastus & 3 days & TKA & $1,3,4,5$ \\
\hline Fukui 2016 & $25 / 25$ & $73.3 / 69.3$ & $15 / 14$ & NS & Posterolateral & NS & $\begin{array}{l}\text { Posterolateral } \\
\text { fusion }\end{array}$ & $1,4,5$ \\
\hline Wang 2016 & $50 / 50$ & $63.5 / 63.9$ & $19 / 15$ & $\mathrm{Hb}<7 \mathrm{~g} / \mathrm{dl}$ & Posterolateral & 1 month & $\begin{array}{l}\text { Degenerative lumbar } \\
\text { scoliosis }\end{array}$ & $1,2,3,4,5,6$ \\
\hline Hill 2012 & $30 / 30$ & $62.6 / 61.8$ & $8 / 11$ & $\mathrm{Hb}<8.0 \mathrm{~g} / \mathrm{dl}$ & Posterolateral & NS & $\begin{array}{c}\text { Spinal stenosis, } \\
\text { spondylolisthesis, and } \\
\text { degenerative scoliosis }\end{array}$ & $1,2,3,4,5,6$ \\
\hline
\end{tabular}

BP, bipolar sealer, C, control group; NS, not stated; THA, total hip arthroplasty; TKA, total knee arthroplasty; Hb, hemoglobin; 1 intraoperative blood loss; 2 need for transfusion; 3 , Hb drop; 4, operating time; 5 , length of hospital stay; 6 , the occurrence of infection.

Table 2: Subgroup analysis of intraoperative blood loss M-H Mantel-Haenszel, CI confidence interval

\begin{tabular}{|c|c|c|c|c|}
\hline Outcome or subgroup & Studies & Number & Statistical method & Effect estimate \\
\hline Knee & 2 & 132 & $\begin{array}{l}\text { Weighted mean difference } \\
(\mathrm{M}-\mathrm{H}, \text { Random, } 95 \% \mathrm{CI})\end{array}$ & $-183.28(-340.04,-26.52)$ \\
\hline Hip & 5 & 613 & $\begin{array}{l}\text { Weighted mean difference } \\
(\mathrm{M}-\mathrm{H}, \text { Random, } 95 \% \mathrm{CI})\end{array}$ & $-69.61(-144.52,5.29)$ \\
\hline Spine & 3 & 210 & $\begin{array}{l}\text { Weighted mean difference } \\
\text { (M-H, Fixed, 95\% CI) }\end{array}$ & $-131.61(-298.42,35.20)$ \\
\hline Low quality & 3 & 200 & $\begin{array}{l}\text { Weighted mean difference } \\
(\mathrm{M}-\mathrm{H}, \text { Random, } 95 \% \mathrm{CI})\end{array}$ & $-72.85(-135.41,21.86)$ \\
\hline Middle quality & 4 & 523 & $\begin{array}{l}\text { Weighted mean difference } \\
\text { (M-H, Random, 95\% CI) }\end{array}$ & $-128.55(-308.69,42.19)$ \\
\hline High quality & 3 & 132 & $\begin{array}{l}\text { Weighted mean difference } \\
(\mathrm{M}-\mathrm{H}, \text { Random, } 95 \% \mathrm{CI})\end{array}$ & $-200.18(-300.99,-152.63)$ \\
\hline
\end{tabular}

\section{Length of hospital stay}

Data on the length of the hospital stay were available for 9 trials $[11,23,26,28,31,32]$, which included a total of 755 patients. A pooled WMD for all patients was completed, and the data showed significant heterogeneity $\left(\mathrm{I}^{2}=59.0 \%\right)$. Bipolar sealer was associated with a lower length of hospital stay compared to standard electrocautery (WMD, $-0.21 ; 95 \% \mathrm{CI},-0.50$ to $0.08 ; P=$ 0.16 , Figure 12).

\section{The occurrence of infection}

Data on the occurrence of infection were available for 7 trials $[12,23,26,29]$, which included a total of 549 patients. A pooled RR for all patients was completed, and 
the data showed no significant heterogeneity $\left(\mathrm{I}^{2}=0 \%\right)$. Bipolar sealer reduced the probability of infection by $2.19 \%$ (RR, 0.41; 95\% CI, 0.15-1.15; $P=0.09$, Figure 13).

\section{DISCUSSION}

In the current meta-analysis, we evaluated the efficacy and safety of bipolar sealer for patients that received major orthopedic surgery. Based on the pooled estimates, bipolar sealer, compared to standard electrocautery, was associated with a significant reduction in the total blood loss, need for transfusion and hemoglobin drop. The use of bipolar sealer was not associated with a significant reduction in operating time, length of hospital stay and the occurrence of infection.

The current meta-analysis demonstrated that bipolar sealer had a beneficial effect on the total blood loss and the subsequent need for blood transfusion. In a previous

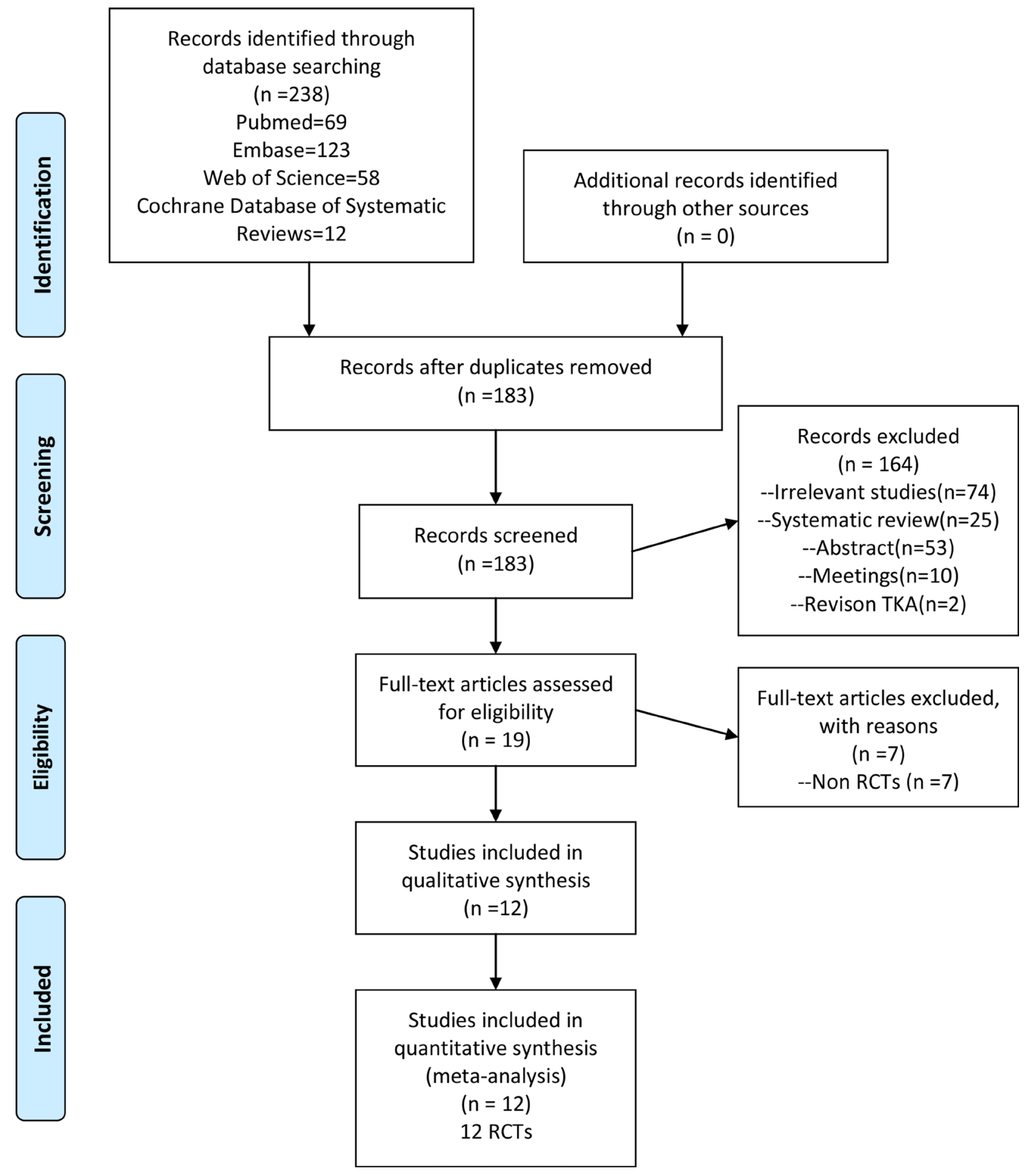

Figure 1: Flow diagram for study selection. 


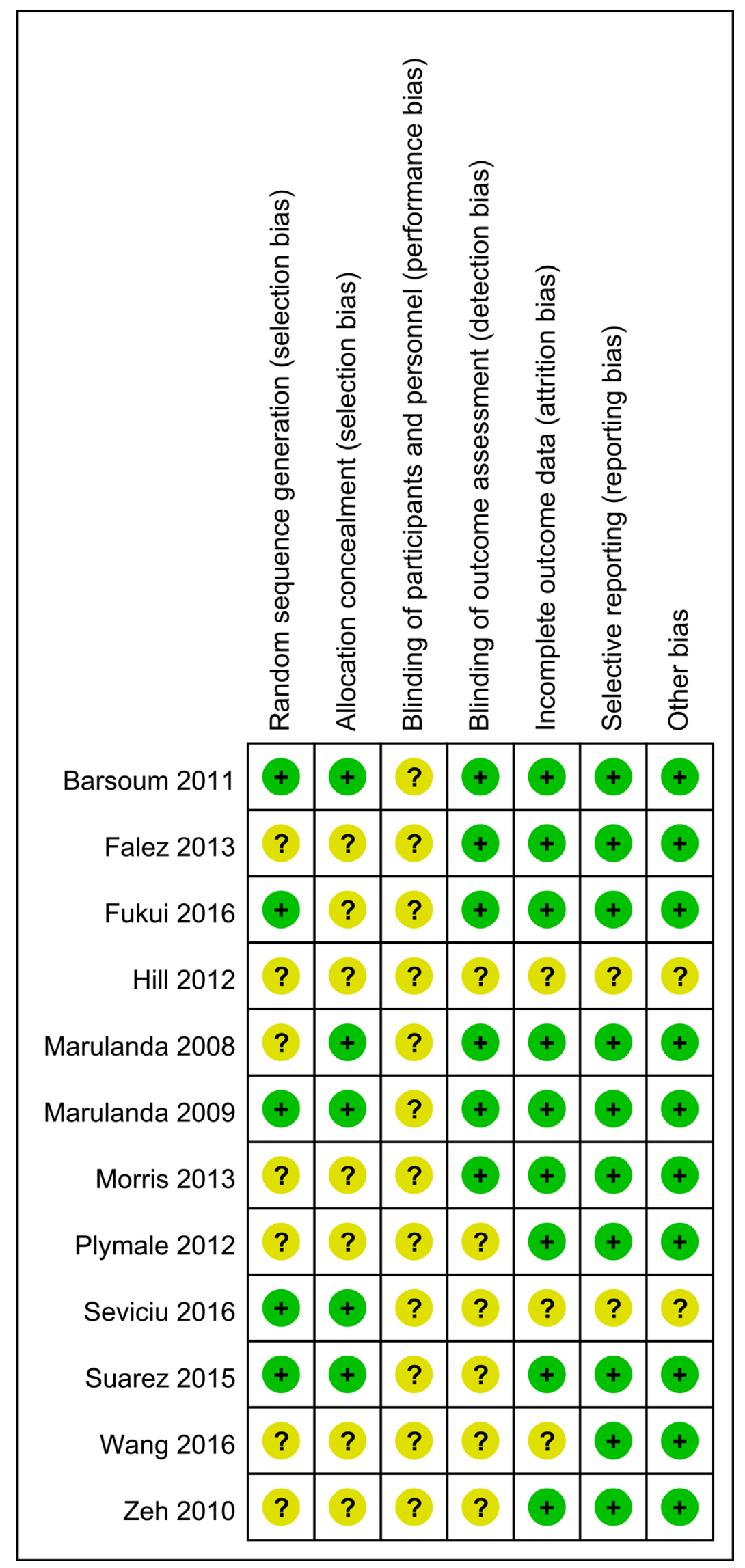

Figure 2: Risk of bias summary. 
meta-analysis of 6 studies that compared bipolar sealer treatment with standard electrocautery in patients with major orthopedic surgery, Min and colleagues [13] found that bipolar sealer appeared to be effective for reducing blood loss and the need for transfusion after THA. However, Yang et al [33] observed that bipolar sealer did not significantly reduce intraoperative blood loss, and it is not recommended for primary THA. Lu et al. [34] revealed that the use of a bipolar sealer is superior to standard electrocautery for reducing intraoperative blood loss during spine surgery. Thus, we could not determine whether bipolar sealer had a significant influence on controlling blood loss. Therefore, more large scale trials are needed to verify the effects of bipolar sealer on patients for major orthopedic surgery. Current metaanalysis indicated that bipolar sealer was associated with intraoperative blood loss by a mean of $105.30 \mathrm{~mL}$ and reduced the probability of receiving a blood transfusion by 9.25\%. Obviously, the difference had clinical importance.

As for operation time and length of hospital stay, there was no significant difference between patients who received bipolar sealer or standard electrocautery for major orthopedic surgery. A previous meta-analysis that included non-RCTs compared bipolar sealer to standard electrocautery during total joint arthroplasty (including TKA and THA) and found no significant differences between bipolar sealer and standard electrocautery in terms of operation time and length of hospital stay [35].

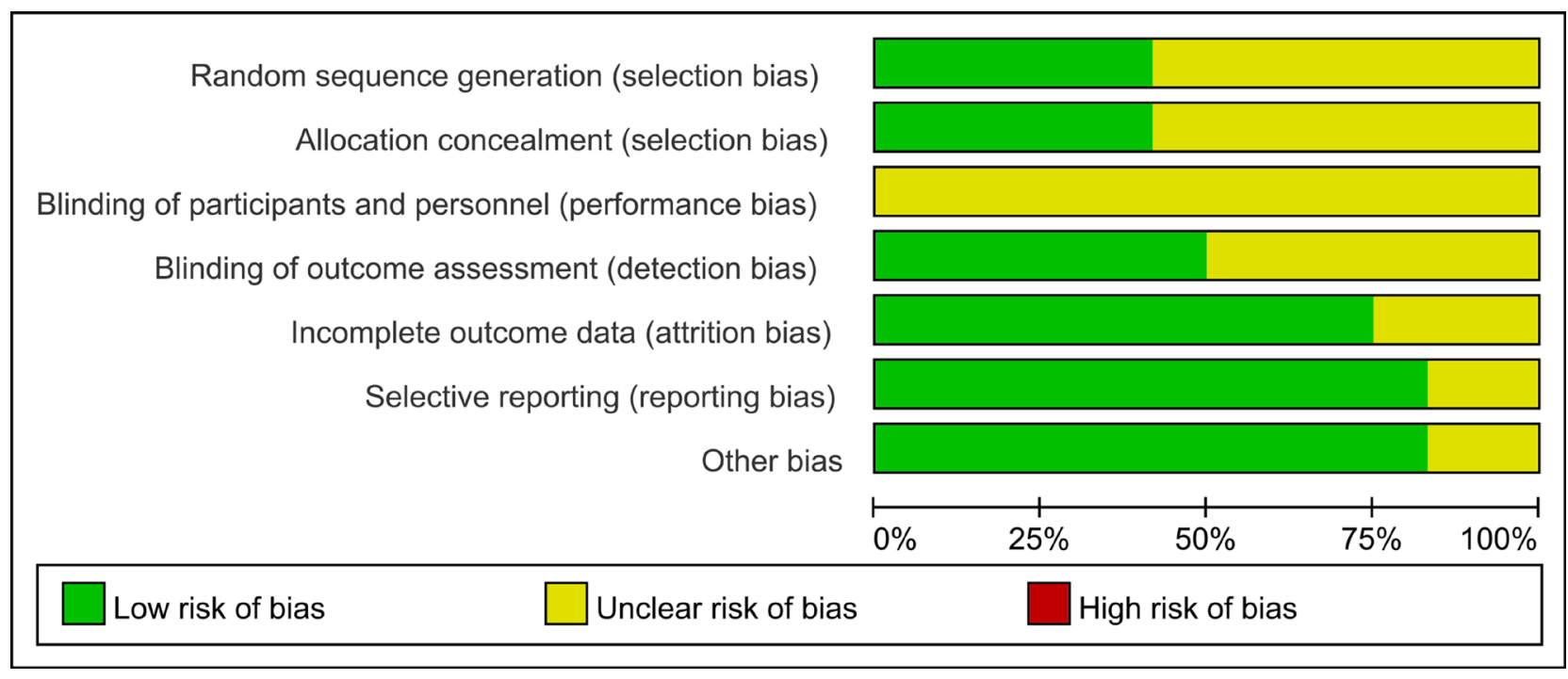

Figure 3: Risk of bias graph.

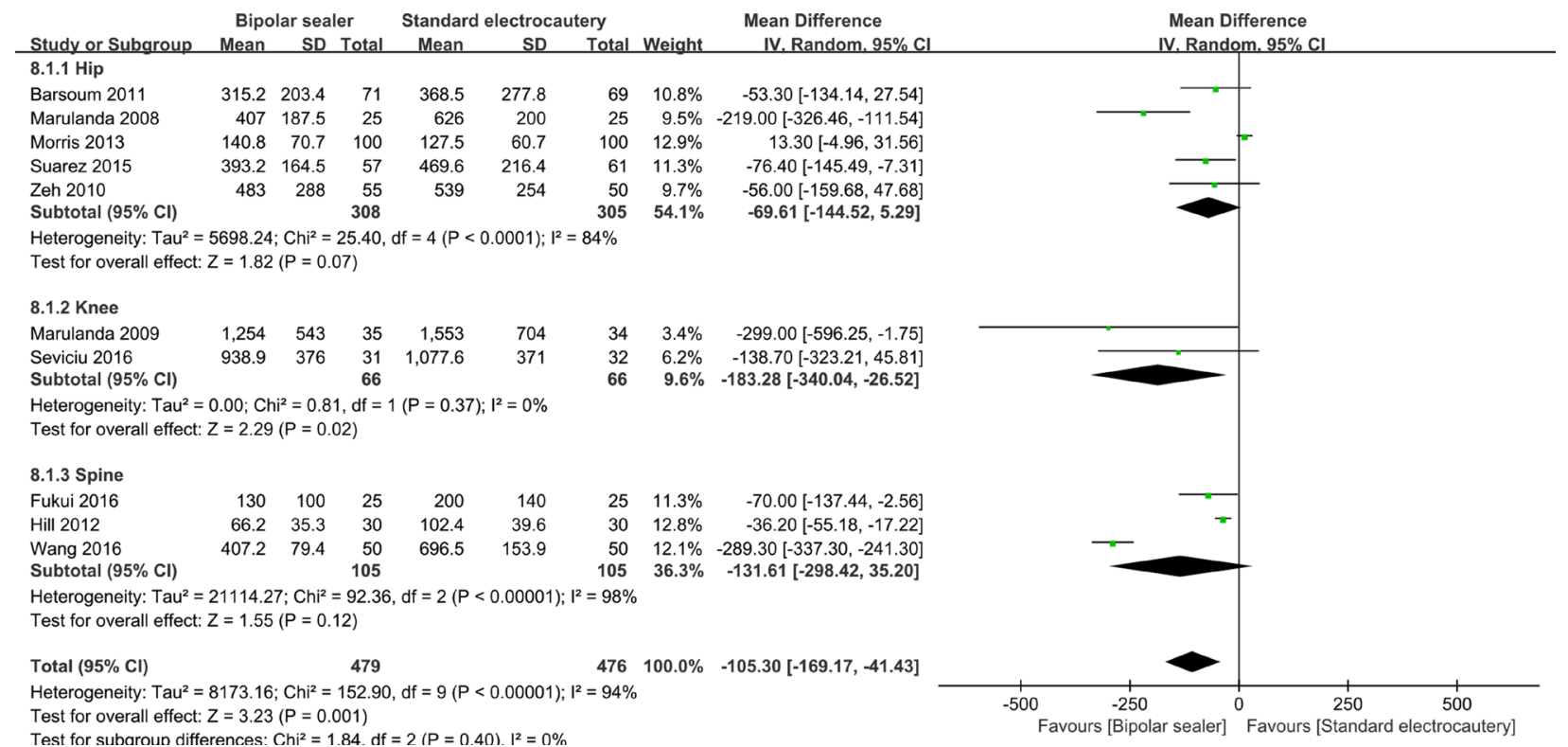

Figure 4: Forest plots comparing intraoperative blood loss between bipolar sealer and standard electrocautery from the included studies. 


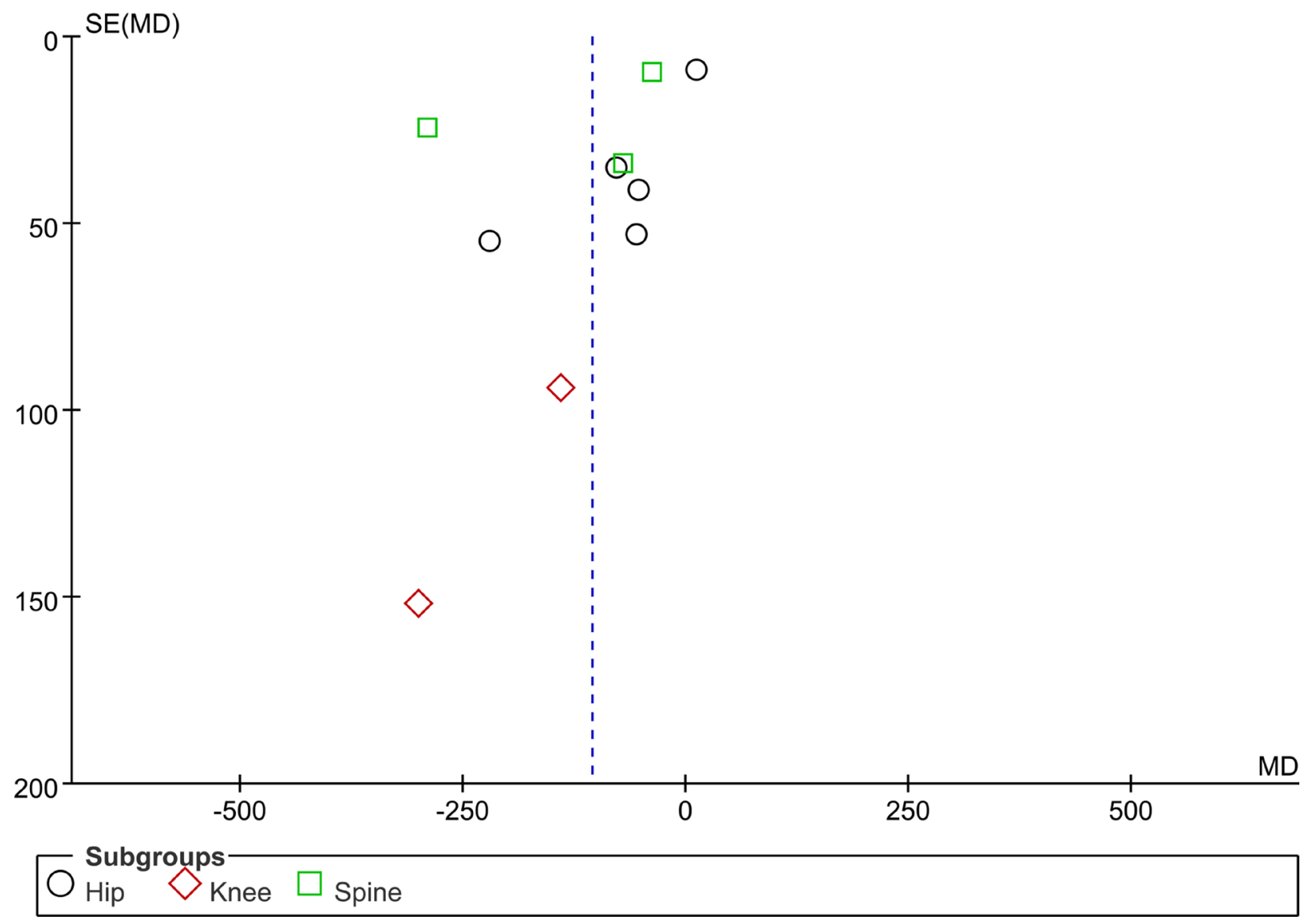

Figure 5: Funnel plot for intraoperative blood loss.

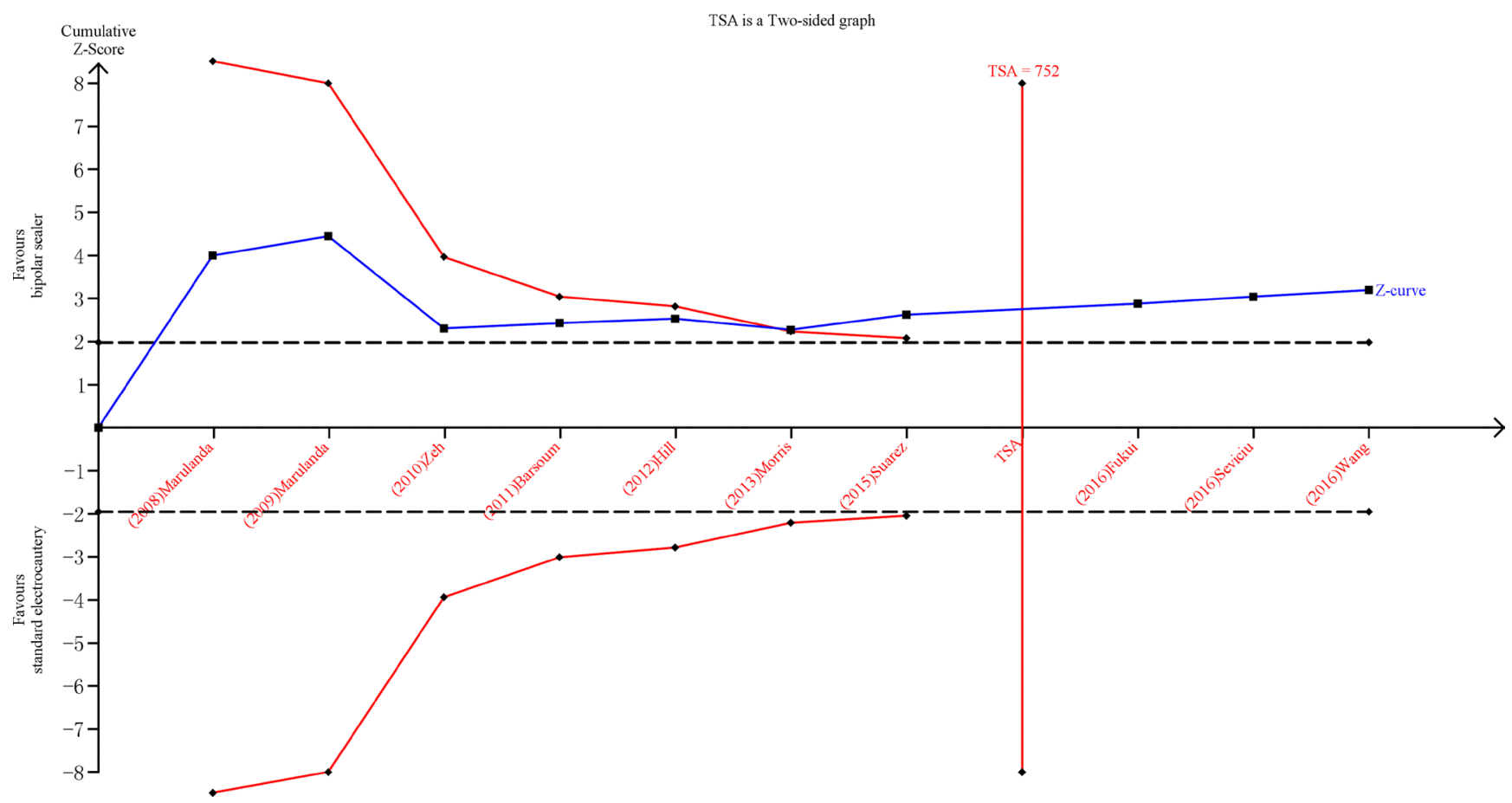

Figure 6: Trial sequential analysis for intraoperative blood loss. 


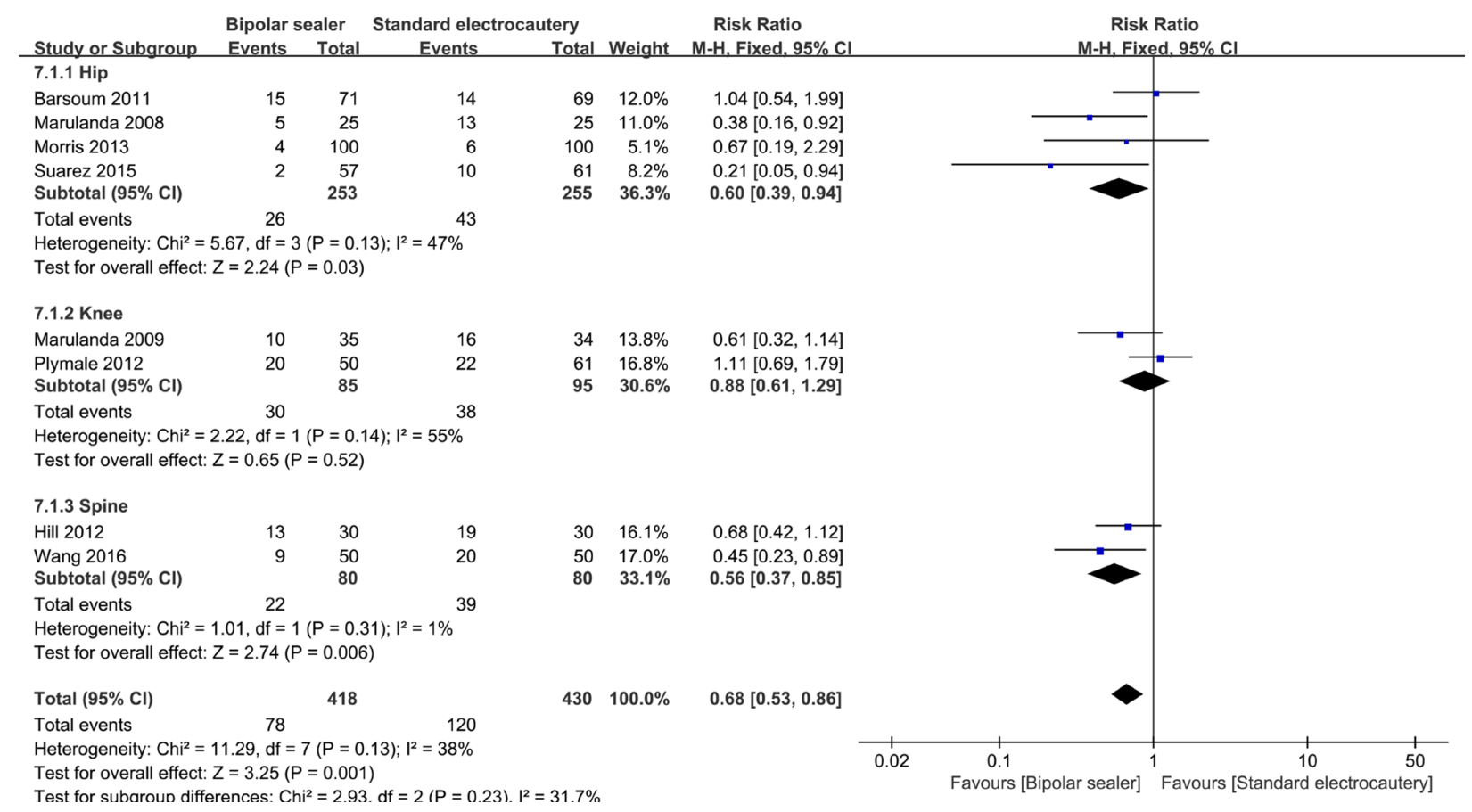

Figure 7: Forest plots comparing the need for transfusion between bipolar sealer and standard electrocautery from the included studies.

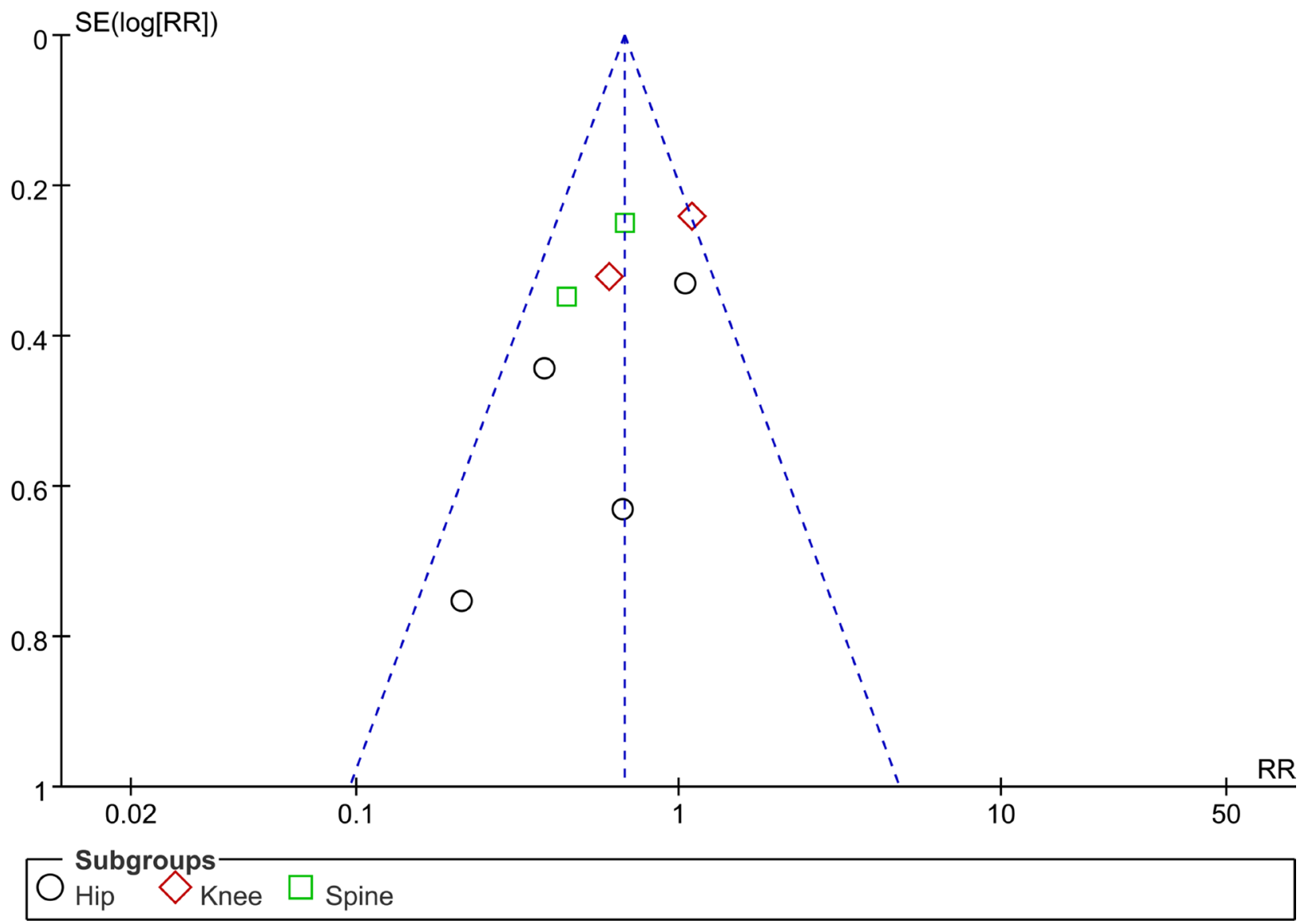

Figure 8: Funnel plot for intraoperative blood loss. 
Seviciu et al [24]. revealed that there were no significant differences between bipolar sealer versus standard electrocautery in terms of operating time and length of hospital stay after TKA. As for infection, there was no significant difference between bipolar sealer and standard electrocautery for major orthopedic surgery.

Another major concern was the cost-effectiveness of using bipolar sealer for major orthopedic surgery. Derman et al [36]. revealed that the bipolar sealer group had a lower operation time and accounted for a savings of $\$ 430$ per patient, and these savings did not offset the $\$ 500$ cost of the device itself (which increased the cost by $\$ 70$ per operation). Morris et al. [30] also revealed that bipolar sealer increased the costs several times compared to standard electrocautery. Ackerman et al. [37] used a hospital administrative database to show that there were no significant differences in total hospital costs between the bipolar sealer group and the standard electrocautery group. Thus, a direct and specific cost-effectiveness comparison is necessary before widely implementing bipolar sealer. F

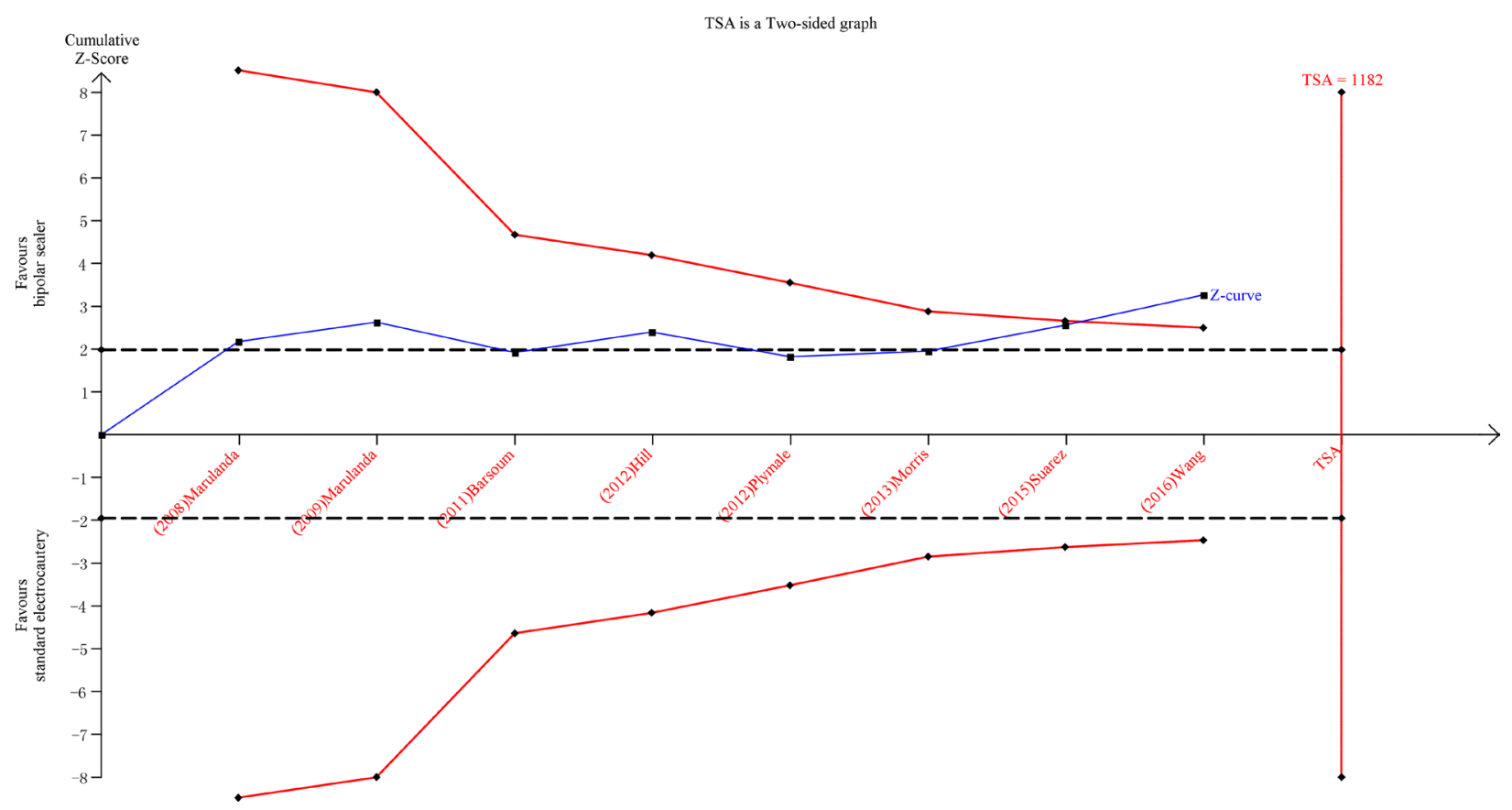

Figure 9: Trial sequential analysis of the need for transfusion.

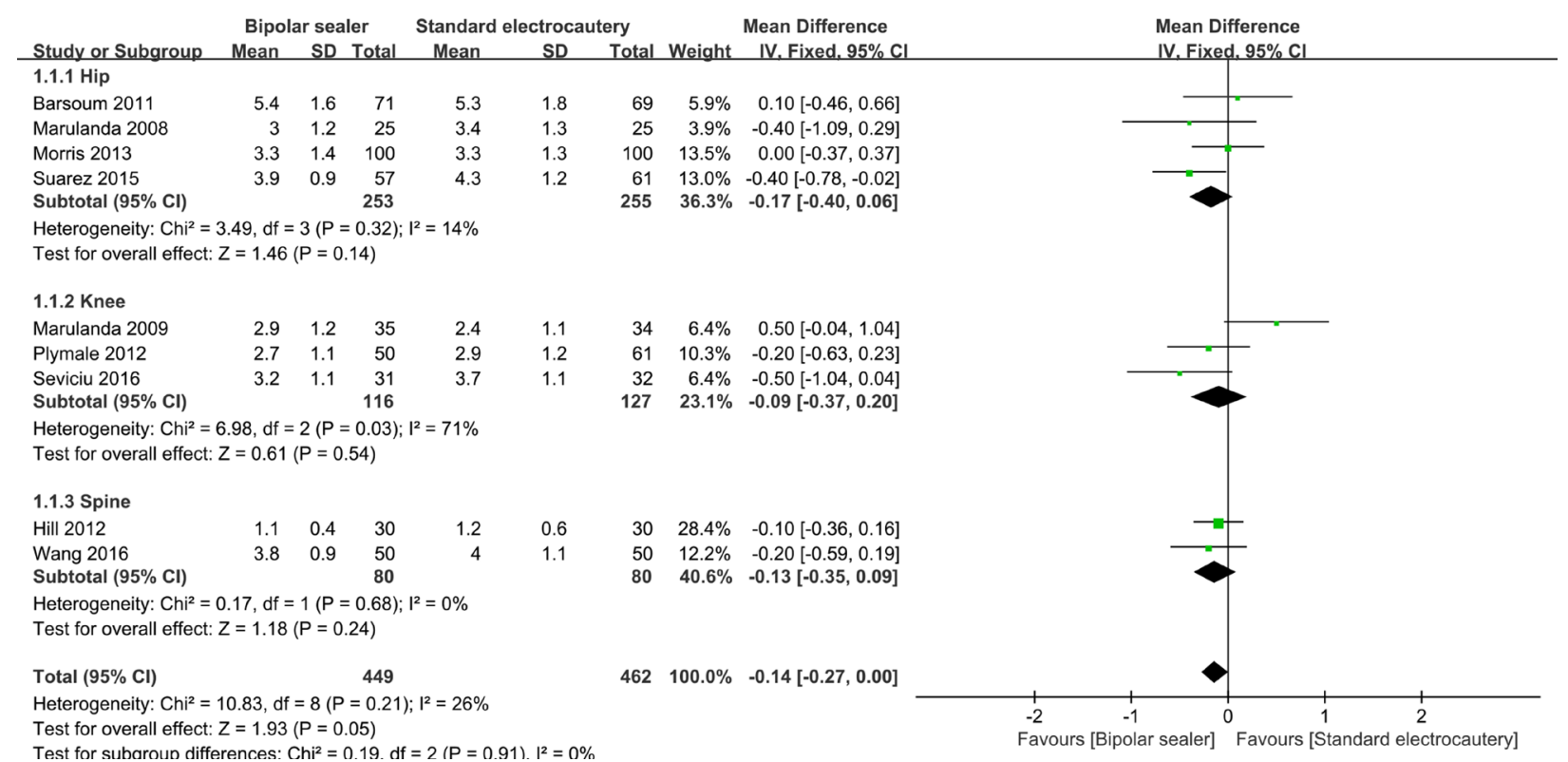

Figure 10: Forest plots comparing hemoglobin drop between bipolar sealer and standard electrocautery from the included studies. 


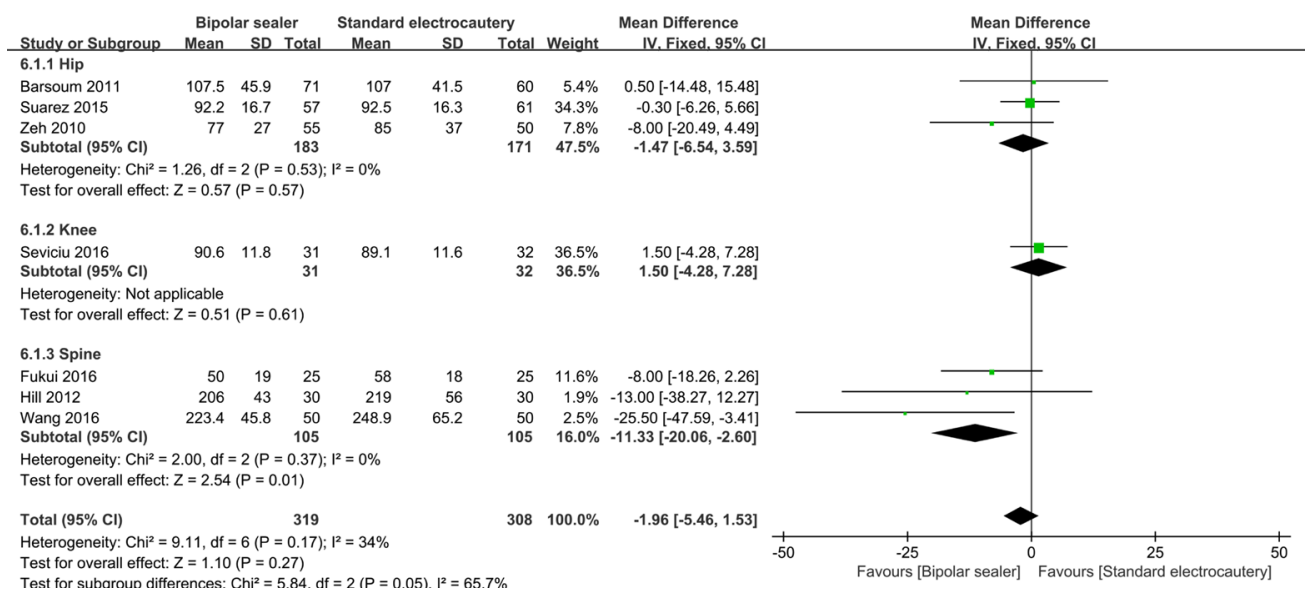

Figure 11: Forest plots comparing the operation time between bipolar sealer and standard electrocautery from the included studies.

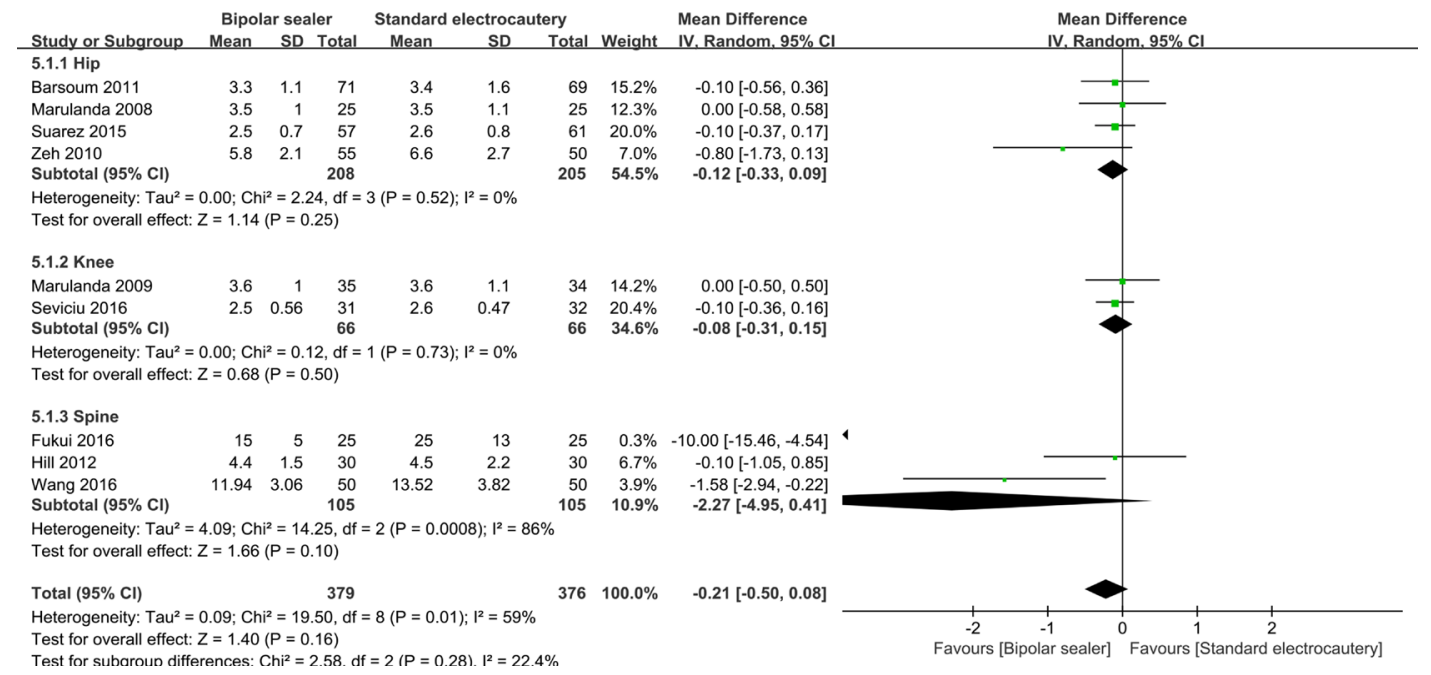

Figure 12: Forest plots comparing the length of hospital stay between bipolar sealer and standard electrocautery from the included studies.

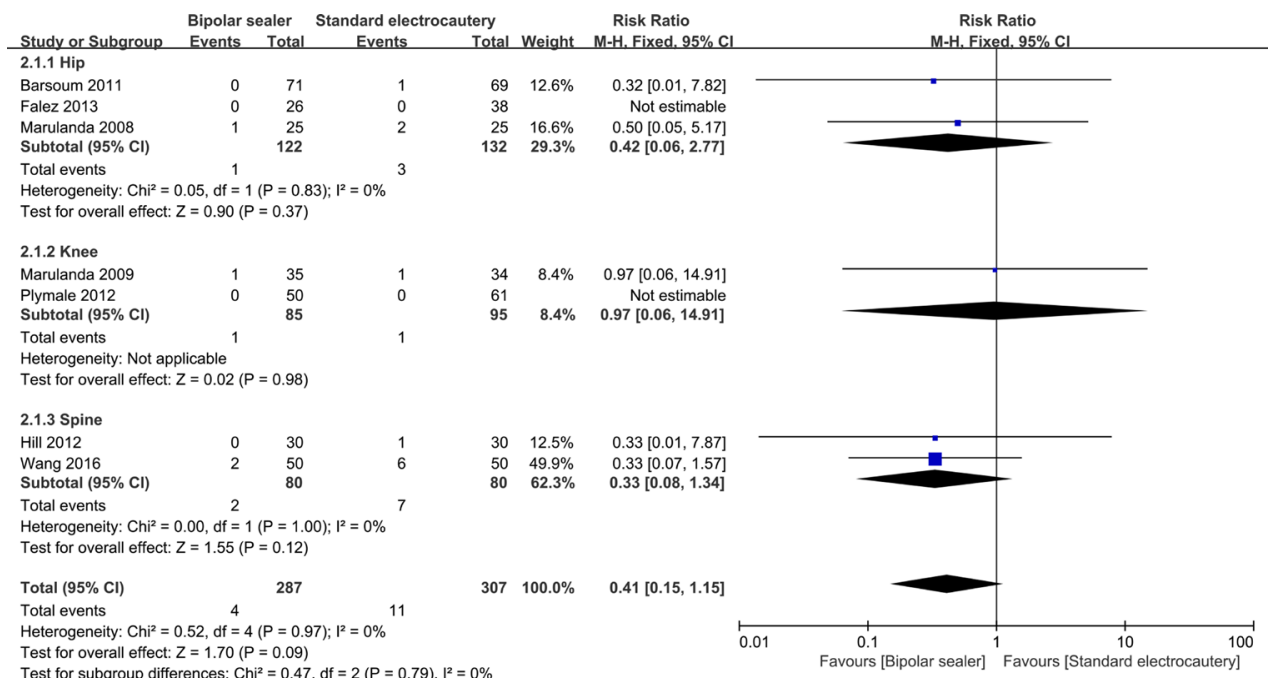

Figure 13: Forest plots comparing the occurrence of infection between bipolar sealer and standard electrocautery from the included studies. 
There were several limitations to this metaanalysis: (1) the blinding of participants and personnel was unclear and may have resulted in performance bias; (2) the duration of follow-up in some studies was relatively short, and long-term follow-up is needed for meta-analysis; and (3) the results for intraoperative blood loss had large heterogeneity that affected the final conclusion. Additionally, a direct and specific costeffectiveness comparison between bipolar sealer and standard electrocautery is necessary before implementing bipolar sealer.

\section{CONCLUSIONS}

In conclusion, the results of our meta-analysis indicate that bipolar sealer can decrease intraoperative blood loss, the need for transfusion, and hemoglobin drop without increasing the occurrence of infection. Additionally, there were no significant differences between the operating time and the length of hospital stay. This was the largest meta-analysis to evaluate the efficacy and safety of bipolar sealer after major orthopedic surgery. Although, cost-effectiveness should be evaluated before implementing bipolar sealer.

\section{Author contributions}

Z.Z. and AX.T. conducted literature search and determined studies for exclusion and inclusion. KQ.F., QS.W. extracted data from the included studies, performed quality assessment, and drafted the manuscript. Y.W., Z.W. and AX.T. conceived the idea of the study, designed the study, and critically revised the manuscript for important intellectual content. All authors reviewed the paper and approved the final manuscript.

\section{CONFLICTS OF INTEREST}

The authors declare no competing financial interests.

\section{FUNDING}

This research work was supported by the grants from the National Natural Science Foundation of China (81472052).

\section{REFERENCES}

1. Li J, Li HB, Zhai XC, Qin L, Jiang XQ, Zhang ZH. Topical use of topical fibrin sealant can reduce the need for transfusion, total blood loss and the volume of drainage in total knee and hip arthroplasty: A systematic review and meta-analysis of 1489 patients. Int J Surg. 2016; 36:127-137.

2. Pierson JL, Hannon TJ, Earles DR. A blood-conservation algorithm to reduce blood transfusions after total hip and knee arthroplasty. J Bone Joint Surg Am. 2004; 86-a: 15121518.

3. Stokes ME, Ye X, Shah M, Mercaldi K, Reynolds MW, Rupnow MF, Hammond J. Impact of bleeding-related complications and/or blood product transfusions on hospital costs in inpatient surgical patients. BMC Health Serv Res. 2011; 11:135.

4. Shang J, Wang H, Zheng B, Rui M, Wang Y. Combined intravenous and topical tranexamic acid versus intravenous use alone in primary total knee and hip arthroplasty: A meta-analysis of randomized controlled trials. Int J Surg. 2016; 36:324-329.

5. Guay J, Haig M, Lortie L, Guertin MC, Poitras B. Predicting blood loss in surgery for idiopathic scoliosis. Can J Anaesth. 1994; 41:775-781.

6. Hur SR, Huizenga BA, Major M. Acute normovolemic hemodilution combined with hypotensive anesthesia and other techniques to avoid homologous transfusion in spinal fusion surgery. Spine. 1992; 17:867-73.

7. Hu SS. Blood loss in adult spinal surgery. Eur Spine J. 2004; 13:S3-5.

8. Madjdpour C, Spahn DR. Allogeneic red blood cell transfusions: efficacy, risks, alternatives and indications. $\mathrm{Br}$ J Anaesth. 2005; 95:33-42.

9. Bierbaum BE, Callaghan JJ, Galante JO, Rubash HE, Tooms RE, Welch RB. An analysis of blood management in patients having a total hip or knee arthroplasty. J Bone Joint Surg Am. 1999; 81:2-10.

10. Cermáková Z, Simetka O, Kořístka M. [Transfusion-related acute lung injury (TRALI) - review]. [Article in Czech]. Ceska Gynekol. 2013; 78:211-15.

11. Marulanda GA, Ulrich SD, Seyler TM, Delanois RE, Mont MA. Reductions in blood loss with a bipolar sealer in total hip arthroplasty. Expert Rev Med Devices. 2008; 5:125-131.

12. Plymale MF, Capogna BM, Lovy AJ, Adler ML, Hirsh DM, Kim SJ. Unipolar vs bipolar hemostasis in total knee arthroplasty: a prospective randomized trial. J Arthroplasty. 2012; 27:1133-7.e1.

13. Min JK, Zhang QH, Li HD, Li H, Guo P. The Efficacy of Bipolar Sealer on Blood Loss in Primary Total Hip Arthroplasty: A Meta-Analysis. Medicine (Baltimore). 2016; 95:e3435.

14. Sun XL, Zhao ZH, Ma JX, Li FB, Li YJ, Meng XM, Ma XL. Continuous Local Infiltration Analgesia for Pain Control After Total Knee Arthroplasty: A Meta-analysis of Randomized Controlled Trials. Medicine (Baltimore). 2015; 94:e2005.

15. Shuster JJ. Cochrane handbook for systematic reviews for interventions, Version 5.1.0. John Wiley \& Sons, Ltd. 2011; 2:126-30.

16. Higgins JP, Altman DG, Gøtzsche PC, Jüni P, Moher D, Oxman AD, Savovic J, Schulz KF, Weeks L, Sterne JA, and Cochrane Bias Methods Group, and Cochrane Statistical Methods Group. The Cochrane Collaboration's tool for 
assessing risk of bias in randomised trials. BMJ. 2011; 343:d5928.

17. Guyatt GH, Oxman AD, Vist GE, Kunz R, Falck-Ytter Y, Alonso-Coello P, Schünemann HJ, and GRADE Working Group. GRADE: an emerging consensus on rating quality of evidence and strength of recommendations. BMJ. 2008; 336:924-26.

18. Guyatt GH, Oxman AD, Kunz R, Vist GE, Falck-Ytter Y, Schünemann HJ, and GRADE Working Group. What is "quality of evidence" and why is it important to clinicians? BMJ. 2008; 336:995-98.

19. Wetterslev J, Thorlund K, Brok J, Gluud C. Trial sequential analysis may establish when firm evidence is reached in cumulative meta-analysis. J Clin Epidemiol. 2008; 61:64 75.

20. Brok J, Thorlund K, Wetterslev J, Gluud C. Apparently conclusive meta-analyses may be inconclusive-trial sequential analysis adjustment of random error risk due to repetitive testing of accumulating data in apparently conclusive neonatal meta-analyses. Int J Epidemiol. 2009; 38:287-298.

21. Higgins JP, Whitehead A, Simmonds M. Sequential methods for random-effects meta-analysis. Stat Med. 2011; 30:903-21.

22. Thorlund $\mathrm{K}$, Imberger $\mathrm{G}$, Walsh $\mathrm{M}$, Chu R, Gluud $\mathrm{C}$, Wetterslev J, Guyatt G, Devereaux PJ, Thabane L. The number of patients and events required to limit the risk of overestimation of intervention effects in meta-analysis - a simulation study. PLoS One. 2011; 6:e25491.

23. Marulanda GA, Krebs VE, Bierbaum BE, Goldberg VM, Ries M, Ulrich SD, Seyler TM, Mont MA. Hemostasis using a bipolar sealer in primary unilateral total knee arthroplasty. Am J Orthop (Belle Mead NJ). 2009; 38:E179-183.

24. Seviciu A, Gross I, Fathima S, Walsh SM. Effects of tranexamic acid and bipolar sealer alone or in combination in primary total knee arthroplasty: a prospective, randomized, controlled trial. Arthroplasty Today. 2016; 2:77-82.

25. Fukui D, Kawakami M, Nakao SI, Miyamoto E, Morishita S, Matuoka T, Yamada H. Reduced blood loss and operation time in lumbar posterolateral fusion using a bipolar sealer. Eur Spine J. 2017; 26:726-32.

26. Hill SE, Broomer B, Stover J, White W, Richardson W. Bipolar tissue sealant device decreases hemoglobin loss in multilevel spine surgery. Transfusion. 2012; 52:2594-2599.

27. Wang X, Sun G, Sun R, Ba C, Gong X, Liu W, Zhai R. Bipolar Sealer Device Reduces Blood Loss and Transfusion
Requirements in Posterior Spinal Fusion for Degenerative Lumbar Scoliosis: A Randomized Control Trial. Clin Spine Surg. 2016; 29:E107-111.

28. Barsoum WK, Klika AK, Murray TG, Higuera C, Lee HH, Krebs VE. Prospective randomized evaluation of the need for blood transfusion during primary total hip arthroplasty with use of a bipolar sealer. J Bone Joint Surg Am. 2011; 93:513-518.

29. Falez F, Meo A, Panegrossi G, Favetti F, La Cava F, Casella F. Blood loss reduction in cementless total hip replacement with fibrin spray or bipolar sealer: a randomised controlled trial on ninety five patients. Int Orthop. 2013; 37:12131217.

30. Morris MJ, Barrett M, Lombardi AV Jr, Tucker TL, Berend KR. Randomized blinded study comparing a bipolar sealer and standard electrocautery in reducing transfusion requirements in anterior supine intermuscular total hip arthroplasty. J Arthroplasty. 2013; 28:1614-1617.

31. Zeh A, Messer J, Davis J, Vasarhelyi A, Wohlrab D. The Aquamantys system--an alternative to reduce blood loss in primary total hip arthroplasty? J Arthroplasty. 2010; 25:1072-1077.

32. Suarez JC, Slotkin EM, Szubski CR, Barsoum WK, Patel PD. Prospective, Randomized Trial to Evaluate Efficacy of a Bipolar Sealer in Direct Anterior Approach Total Hip Arthroplasty. J Arthroplasty. 2015; 30:1953-1958.

33. Yang Y, Zhang LC, Xu F, Li J, Lv YM. Bipolar sealer not superior to standard electrocautery in primary total hip arthroplasty: a meta-analysis. J Orthop Surg Res. 2014; 9:92.

34. Lu D, Ding WG, Sheng HF, Xu XW, Ying XZ, Xu WX. The efficacy and safety of using a bipolar sealer to prevent blood loss in spine surgery: A meta-analysis. Int J Surg. 2017; 46:37-46.

35. Huang Z, Ma J, Shen B, Yang J, Zhou Z, Kang P, Pei F. Use of a Bipolar Blood-Sealing System During Total Joint Arthroplasty. Orthopedics. 2015; 38:757-763.

36. Derman PB, Kamath AF, Lee GC. Saline-coupled bipolar sealing in revision total knee arthroplasty for infection. Am J Orthop (Belle Mead NJ). 2013; 42:407-411.

37. Ackerman SJ, Tapia CI, Baik R, Pivec R, Mont MA. Use of a bipolar sealer in total hip arthroplasty: medical resource use and costs using a hospital administrative database. Orthopedics. 2014; 37:e472-481. 